\title{
Fracture mechanics and microstructure in NiTi shape memory alloys
}

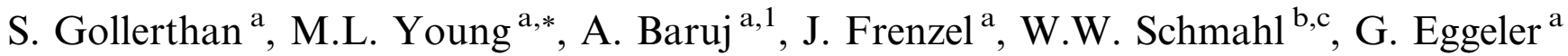 \\ ${ }^{a}$ Institut für Werkstoffe, Ruhr-Universität Bochum, Universitätsstraße 150, D-44801 Bochum, Germany \\ ${ }^{\mathrm{b}}$ Institut für Geologie, Mineralogie und Geophysik, Ruhr-Universität Bochum, D-44780 Bochum, Germany \\ ${ }^{\mathrm{c}}$ Department of Earth and Environmental Sciences, Materials Research, LMU Munich, Germany
}

Received 9 September 2008; received in revised form 16 October 2008; accepted 16 October 2008

Available online 26 December 2008

\begin{abstract}
Crack extension under static loading in pseudoplastic and pseudoelastic binary NiTi shape memory alloy (SMA) compact tension (CT) specimens was examined. Two material compositions of 50.3 at.\% Ni (martensitic/pseudoplastic) and 50.7 at.\% Ni (austenitic/ pseudoelastic) were investigated. The SMAs were characterized using differential scanning calorimetry to identify the phase transformation temperatures and tensile testing to characterize the stress-strain behavior. A miniature CT specimen was developed, which yields reliable critical fracture mechanics parameters. At $295 \mathrm{~K}$, cracks propagate at similar stress intensities of $30 \pm 5 \mathrm{MPa} \sqrt{\mathrm{m}}$ into martensite and pseudoelastic austenite. Integrating the miniature CT specimen into a small test device which can be fitted into a scanning electron microscope shows that this is due to cracks propagating into regions of detwinned martensite in both materials. Investigating a pseudoelastic miniature CT specimen in a synchrotron beam proves that martensite forms in front of the crack in the center of the CT specimen, i.e. under plane strain conditions.

(C) 2008 Acta Materialia Inc. Published by Elsevier Ltd. All rights reserved.
\end{abstract}

Keywords: Shape memory alloys (SMA); Mechanical properties testing; Stress-induced martensite; Tension test

\section{Introduction}

Microstructures and properties of NiTi shape memory alloys (SMAs) have been described in detail [1-6]. NiTi SMAs are used in a wide range of applications in medical technology and engineering [5-7], because they combine good functional properties with good mechanical strength $[1-6,8]$. Their mechanical properties have been investigated using tensile (e.g. [9-11]) and fatigue testing (e.g. [9,12-17]). The formation of microcracks during cyclic loading has been observed [15] and crack propagation under cyclic loading conditions has been monitored [16,18-25]. However, the behavior of cracks under static loading conditions in martensitic, pseudoplastic $(50.3 \mathrm{at} . \% \mathrm{Ni})$ and austenitic, pseudoelastic (50.7 at.\% Ni) NiTi microstructures is not yet

\footnotetext{
* Corresponding author. Tel.: +49 176 24894769; fax: +49 2343214235 . E-mail address: marcus.young@rub.de (M.L. Young).

${ }^{1}$ On leave from: TEMADI, Centro Atómico Bariloche, 8400 S.C. Bariloche, Argentina; and CONICET, Argentina.
}

clear. A systematic study on critical parameters, like $K_{\mathrm{IC}}$ values, has not yet been performed, and there is a need for identification of conditions under which cracks in martensitic and pseudoelastic NiTi SMAs become unstable. As of yet, only critical stress intensities of $31[19,26]$ and $35 \mathrm{MPa} \sqrt{\mathrm{m}}$ [24] for martensitic NiTi SMAs and $34 \mathrm{MPa} \sqrt{\mathrm{m}}[27,28]$ for pseudoelastic NiTi SMAs have been reported; the latter value comes from fatigue-loaded very-thin-walled $(\sim 400 \mu \mathrm{m})$ compact tension $(\mathrm{CT})$ specimens, which is most probably in a plane stress condition $[27,28]$.

The elementary processes governing crack initiation and crack instability are not well understood. Thus, McKelvey and Ritchie $[20,21]$ investigated fatigue crack propagation in pseudoelastic and pseudoplastic NiTi SMAs using disk-shaped compact tension specimens of $9 \mathrm{~mm}$ thickness. They found that fatigue crack growth resistance increases with decreasing temperature and that fatigue thresholds were higher and crack growth rates slower in martensite as compared to austenite. They did not observe the forma- 
tion of martensite in front of fatigue cracks growing into pseudoelastic NiTi and relate this absence of stress-induced martensite to the triaxial stress state, which characterizes their plane strain condition. Dauskardt et al. [22] suggest that the formation of martensite in front of a crack tip is a beneficial process which renders the material more damage tolerant and that the absence of stress-induced martensite decreases the material's resistance to crack propagation. It is well known that small plastic zones can form in CT specimens of ductile engineering alloys even under plane strain conditions. Such specimens yield reasonable fracture mechanics parameters as long as the size of the plastic zone $\left(r_{\mathrm{p}}\right)$ is significantly smaller than the specimen dimensions ( $a, B$ and $W$ ), where $a, B$ and $W$ represent crack length, specimen thickness and specimen width, respectively $[29,30]$. When plastic zones can form by dislocation activity in front of cracks under plane strain conditions, there is no reason why the formation of stress-induced martensite in front of a pseudoelastic crack should be suppressed, because both dislocation slip and martensitic shear are driven by microscopic shear stresses.

The crack tip regions of NiTi SMA CT specimens have been studied using a variety of methods, including optical microscopy $[19,26]$, synchrotron $[16,24,26]$ and neutron [23] diffraction. It has been shown that the size of pseudoplastic zones (regions in front of cracks with favorably oriented martensitic variants) can be reasonably well estimated using fracture mechanics approaches $[19,26]$. Daymond et al. [24] showed that detwinning indeed occurs in front of cracks in pseudoplastic martensitic NiTi, though Vaidyanathan et al. [23] were unable to observe this due to the limited lateral resolution in their neutron experiments. Robertson et al. [16] studied a thin miniature pseudoelastic NiTi CT specimen subjected to cyclic loading using synchrotron X-ray microdiffraction. In contrast to the conclusions of McKelvey and Ritchie [20,21], they observed the formation of stress-induced martensite very close to the crack tip and were able to resolve the local microtexture [16]. Their thin specimen (thickness: $0.4 \mathrm{~mm}$ ) was most probably in a plane stress condition and thus it remains to be proven whether stress-induced martensite also forms under plane strain conditions, i.e. in the center of a thicker CT specimen. In addition, a comprehensive comparison of the behavior of cracks in martensitic and austenitic NiTi has never been performed and would be very interesting.

The present work has four aspects. First, it provides a comprehensive treatment of the fracture mechanics characteristics of three material states in NiTi: martensitic, pseudoelastic (austenitic, but prone to the formation of stress-induced martensite) and austenitic (without the potential to form stress-induced martensite) NiTi. Secondly, we compare and discuss the response of miniature CT specimens to mechanical loading and provide critical data for crack extension under static loading for all three material states. We then study the evolution of microstructures in front of cracks, which grow into martensitic and pseudoelastic NiTi using in situ experiments in a scanning electron microscope. Finally, we perform in situ synchrotron experiments to clarify whether stress-induced martensite forms in front of the central part of a crack in a thick pseudoelastic CT specimen (i.e. under plane strain conditions).

\section{Materials and experiments}

Two NiTi SMAs with 50.3 at.\% Ni (martensitic/pseudoplastic at room temperature) and 50.7 at.\% Ni (austenitic/ pseudoelastic at room temperature) were purchased from Memory Metalle, Weil am Rhein. Both alloys were subjected to thermomechanical treatments (forming and aging steps) including a final 6 min heat-treatment at $500{ }^{\circ} \mathrm{C}$ for the pseudoelastic alloy. Both materials were characterized using differential scanning calorimetry (DSC), uniaxial tensile testing, CT fracture testing, optical and scanning electron microscopy (SEM), and synchrotron diffraction.

DSC was performed on both SMAs using a TA Instruments' DSC 2920CE machine in a temperature range from 123 to $423 \mathrm{~K}$ at a heating/cooling rate of $10 \mathrm{~K} \mathrm{~min}^{-1}$, whereby specimens were held for $5 \mathrm{~min}$ at the maximum und minimum temperatures. The details of DSC testing have been described elsewhere [31]. Fig. 1a shows the DSC chart of the martensitic material investigated in the present study. When forward and reverse transformations represent one-step events, the characteristic transformation temperatures are defined as $M_{\mathrm{s}}$ (start of the martensitic transformation), $M_{\mathrm{f}}$ (temperature where the forward transformation is completed), $A_{\mathrm{s}}$ (start of the austenitic transformation) and $A_{\mathrm{f}}$ (temperature where the reverse transformation is completed). For the martensitic alloy investigated in the present study, the characteristic temperatures were obtained as $M_{\mathrm{s}}=317 \mathrm{~K}, M_{\mathrm{f}}=289 \mathrm{~K}$, $A_{\mathrm{s}}=333 \mathrm{~K}$ and $A_{\mathrm{f}}=357 \mathrm{~K}$ (Fig. 1a). As shown in Fig. 1b, the austenitic pseudoelastic alloy shows a complex three-step transformation upon cooling from the high temperature phase, which is typically related to the presence of small- and large-scale microstructural heterogeneities [3136]. We attribute the first peak upon cooling to the formation of R-phase $\left(R_{\mathrm{S}}=284 \mathrm{~K}\right.$ and $\left.R_{\mathrm{f}}=267 \mathrm{~K}\right)$, where $R_{\mathrm{s}}$ and $R_{\mathrm{f}}$ indicate the starting and finishing temperature of the R-phase formation. A small second peak indicates the start of the formation of $\mathrm{B}^{\prime} 9^{\prime}\left(M_{\mathrm{s}}=229 \mathrm{~K}\right)$, which accounts for yet a third peak which ends at the martensite finish temperature $\left(M_{\mathrm{f}}=210 \mathrm{~K}\right)$. While the DSC chart features on cooling appear complex, our pseudoelastic alloy exhibits a simple one-step reverse transformation ( $A_{\mathrm{s}}=276 \mathrm{~K}$ and $A_{\mathrm{f}}=293 \mathrm{~K}$ ). The DSC charts in Fig. 1a and $\mathrm{b}$ show that, at room temperature $(295 \mathrm{~K})$, the alloy with 50.3 at.\% $\mathrm{Ni}$ is martensitic while the alloy with 50.7 at.\% Ni is fully austenitic. No further effort was made to rationalize DSC chart features.

Uniaxial tensile tests, with dog-bone tensile specimens identical in dimensions to those reported previously [19], were performed using a Zwick/Roell Z100 electromechanical test rig with a temperature chamber. These flat tensile 

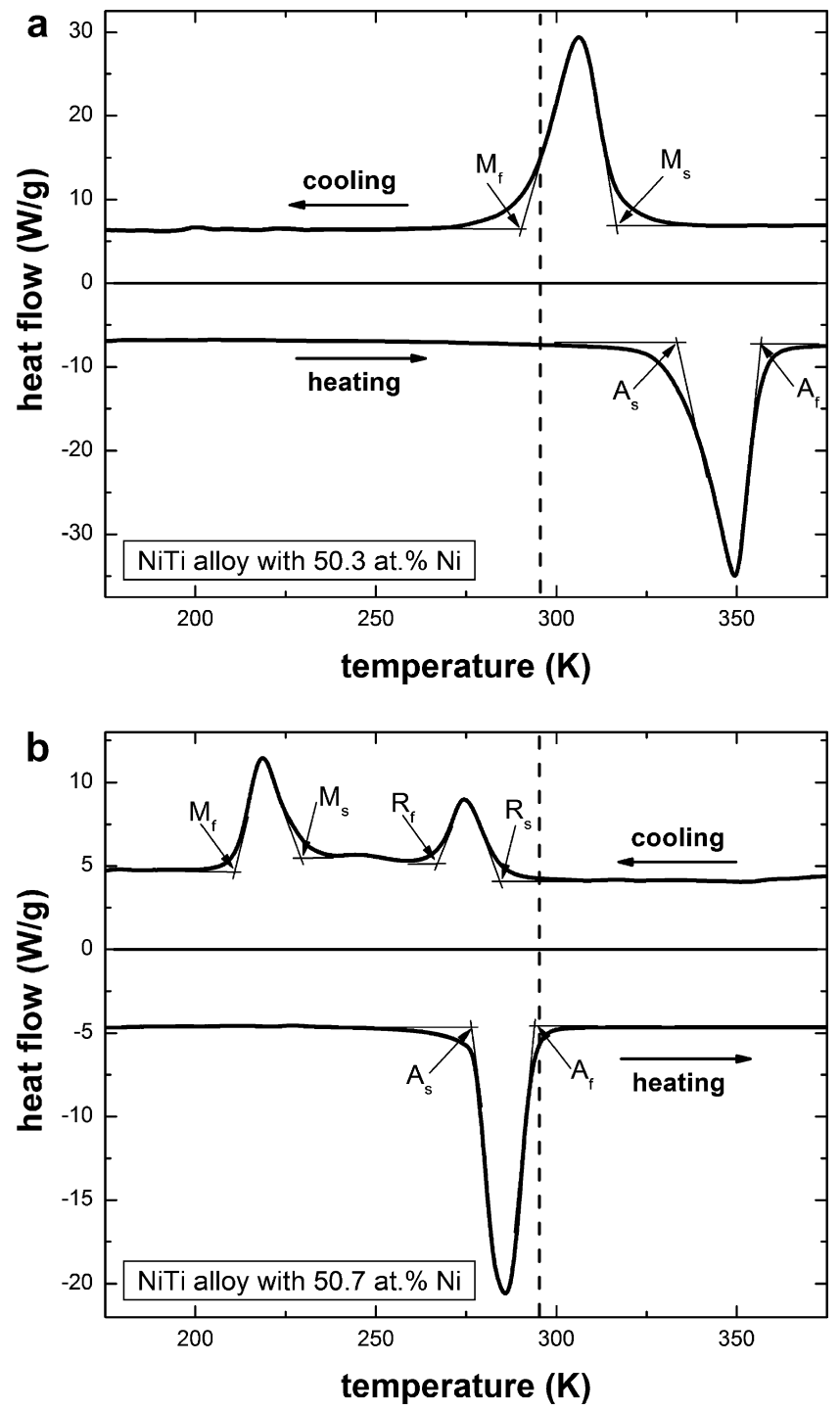

Fig. 1. DSC curves for the (a) 50.3 at. $\% \mathrm{Ni}$ (martensitic NiTi at $295 \mathrm{~K}$ ) and (b) 50.7 at. $\% \mathrm{Ni}$ (pseudoelastic NiTi) SMAs. The dashed line indicates room temperature $(295 \mathrm{~K})$.

specimens, with a gauge length of $10 \mathrm{~mm}$, a width of $3 \mathrm{~mm}$ and a thickness of $2 \mathrm{~mm}$, were machined with double shoulders using electrical discharge machining. Elongations were measured using an MTS extensometer $(632.13 \mathrm{~F}-23)$, which was attached directly to the specimens. The pseudoelastic tensile specimens were placed in boiling water before mounting in the tensile rig. The mechanical behavior of the two alloys was examined by standard tensile testing at $295 \mathrm{~K}$ (strain rate: $0.05 \mathrm{~mm} \mathrm{~min}^{-1}$ ) (Fig. 2a and $b$ ). As illustrated in Fig. 2a, the martensitic and pseudoelastic alloys show typical tensile curves, with stress plateaus at $200 \mathrm{MPa}$ (martensitic alloy) and $330 \mathrm{MPa}$ (pseudoelastic alloy). It is clear that the two alloys differ in tensile strength and rupture ductility. Fig. 3 shows specimens after rupture (stress-strain histories reported in Fig. 2a). The martensitic alloy keeps its deformed shape while the pseudoelastic alloy almost fully recovers the total strain imposed during tensile loading. Fig. $2 b$ documents
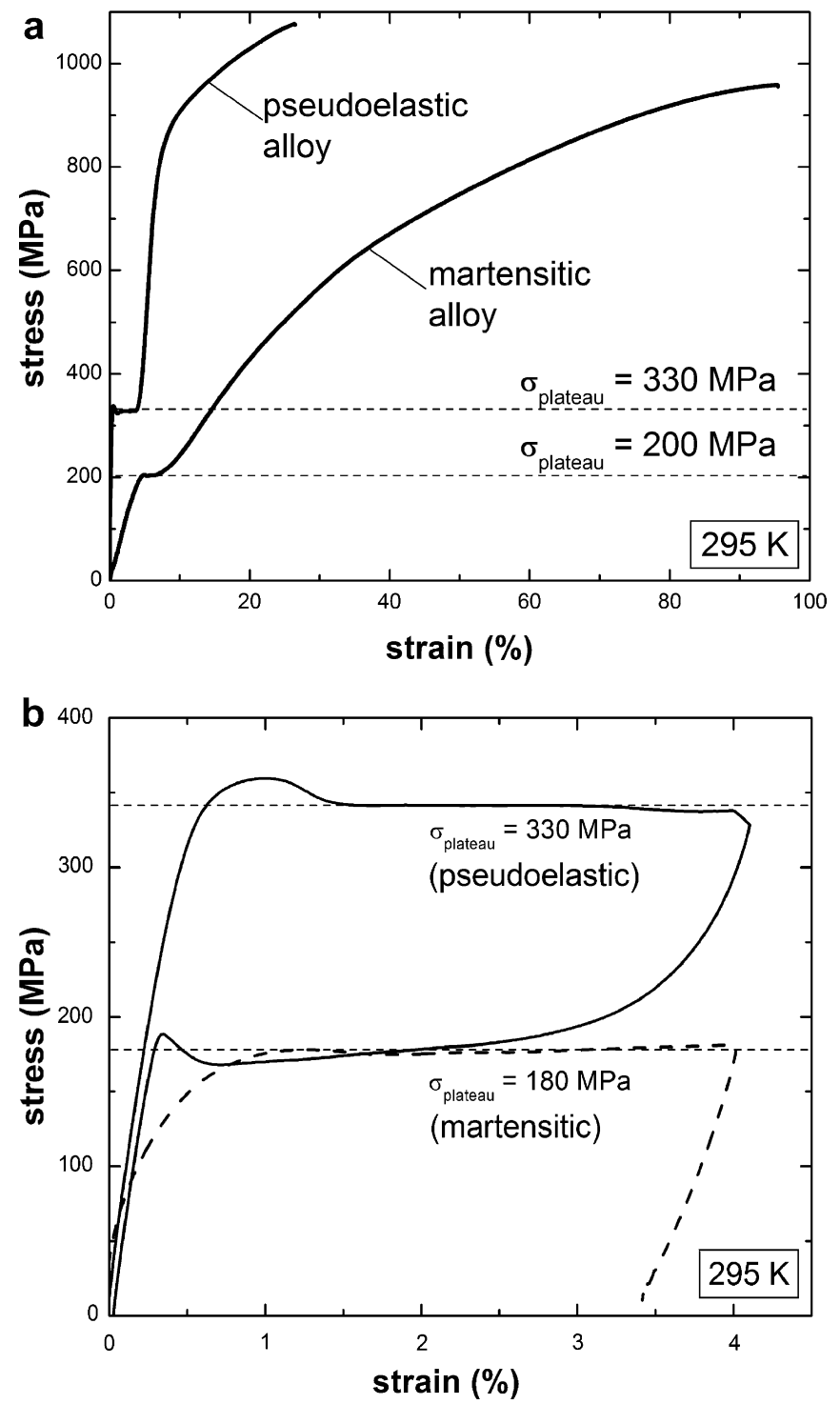

Fig. 2. (a) Stress-strain curves using a strain rate of $0.05 \mathrm{~mm} \mathrm{~min}^{-1}$ up to failure and (b) $4 \%$ strain at $295 \mathrm{~K}$ for martensitic and pseudoelastic NiTi SMAs.

the difference between the martensitic and the pseudoelastic alloys at a higher strain resolution for a loading/unloading experiment taken to a maximum strain of $4 \%$. The pseudoelastic alloy shows nearly complete strain reversibility, while the martensitic alloy exhibits full irreversibility, if the back transformation is not thermally induced (oneway effect) [37].

In our test program, we need to establish the temperature $M_{\mathrm{d}}$ above which stress-induced martensite no longer forms, because mechanical tests above $M_{\mathrm{d}}$ allow for the assessment of the mechanical properties of austenite. For this purpose, we performed additional isothermal loading and unloading tests on our pseudoelastic alloy (maximum strain: $4 \%$; strain rate: $0.05 \mathrm{~mm} \mathrm{~min}^{-1}$ ) at temperatures below, at and above room temperature, some of which are shown in Fig. 4a. The evolution of the loading and unloading stress-strain curves in Fig. 4a illustrates that 


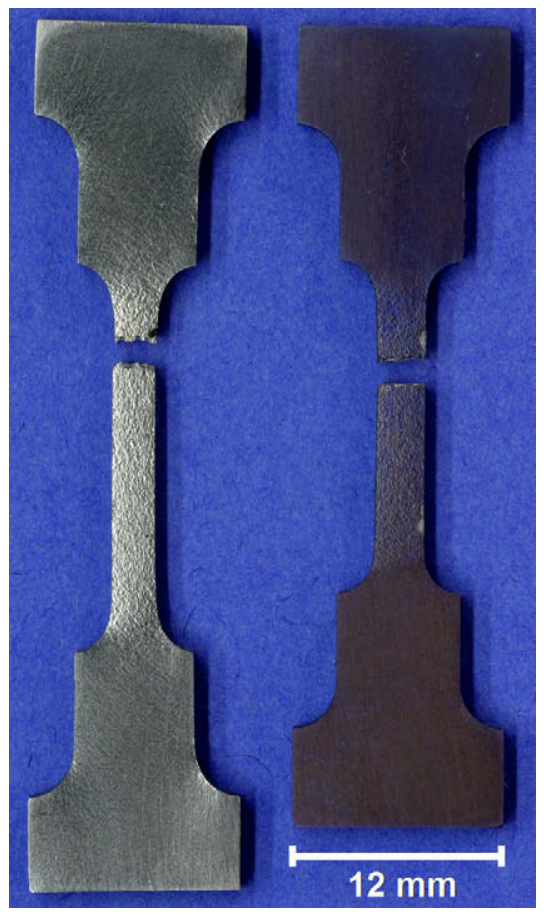

Fig. 3. Optical images of martensitic (left) and pseudoelastic (right) NiTi SMAs tensile specimens after failure. Mechanical histories are shown in Fig. 2a.

the pseudoelastic reversibility which characterizes the room-temperature experiment $(295 \mathrm{~K})$ is no longer observed at 373 and $473 \mathrm{~K}$, where the irreversible strain reflects the plastic deformation of austenite. In contrast, at lower temperatures $(218 \mathrm{~K})$ the same type of pseudoplastic stress-strain curve is observed as exhibited by the martensitic material at room temperature. The observed irreversible strains as a function of temperature from all tests performed to determine $M_{\mathrm{d}}$ are presented in Fig. $4 \mathrm{~b}$. The results shown in Fig. $4 \mathrm{~b}$ suggest that a test temperature of $423 \mathrm{~K}$ (dashed line) is safely above $M_{\mathrm{d}}$ and can be used to assess the mechanical properties of austenitic NiTi. Throughout the present study we refer to our SMA with 50.7 at.\% NiTi as pseudoelastic material (when the formation of stress-induced martensite needs to be considered) and as austenite when the test is performed above $M_{\mathrm{d}}$ (when stress-induced martensite can no longer form).

Fracture mechanics experiments were performed using a miniature CT specimen geometry $[19,26]$, which is similar to the ASTM standard E399-90 [38] but miniaturized. The thickness $B$ of our CT specimen is $8 \mathrm{~mm}$ (close to the $9 \mathrm{~mm}$ of the McKelvey and Ritchie specimen [20]) and its width $W$ is $16 \mathrm{~mm}$. We performed the preliminary series of fracture mechanics tests described by Gollerthan et al. $[19,26]$ on miniature and standard size Al 7075 specimens to ensure that our miniature CT test methodology provided valid data (A1 7075 is known to show linear elastic fracture mechanics behavior [39] and has a similar elastic modulus as our pseudoelastic NiTi). Higher apparent $K_{\mathrm{IC}}$ values are observed for lower thicknesses and increase
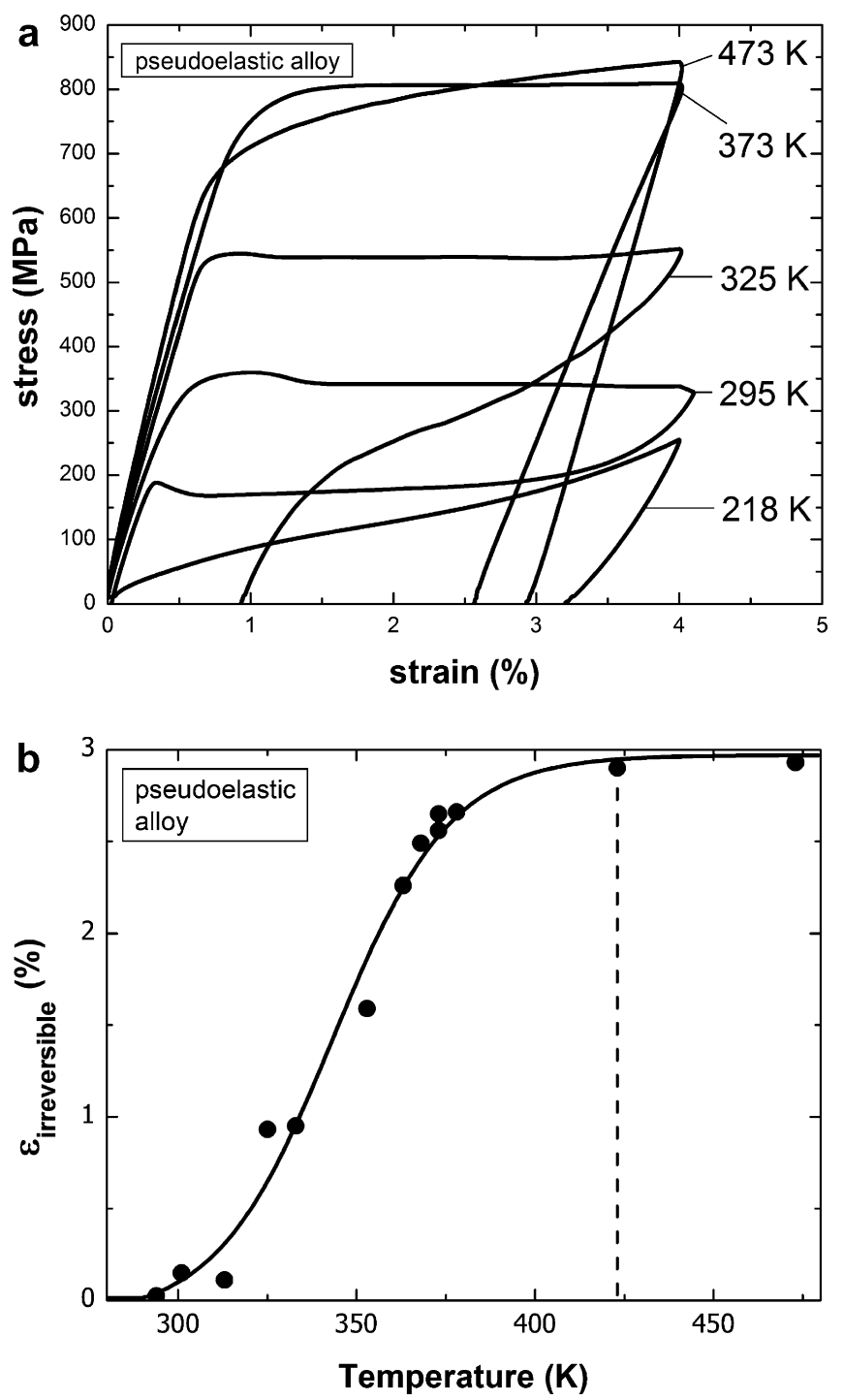

Fig. 4. (a) Stress-strain curves of the pseudoelastic NiTi SMA in a temperature range between $218 \mathrm{~K}$ and $473 \mathrm{~K}$ up to maximum strains of $4 \%$ (strain rate: $0.05 \mathrm{~mm} \mathrm{~min}^{-1}$ ) and (b) irreversible strain after unloading vs. temperature for the pseudoelastic NiTi SMA. Above $373 \mathrm{~K}$, the irreversible strain approaches a constant value of $3 \%$. The black curve is a Boltzmann curve fit. The dashed line indicates the temperature above $M_{\mathrm{d}}$ $(423 \mathrm{~K})$ used for the austenitic NiTi alloy.

with increasing thickness. At thicknesses of $8 \mathrm{~mm}$, the $K_{\mathrm{IC}}$ value no longer decreases with further increasing thickness.

Prior to CT testing, fatigue pre-cracks were introduced using cyclic tensile loading between 0.03 and $0.55 \mathrm{kN}$ at a frequency of $20 \mathrm{~Hz}$ in a servo-hydraulic test rig (Schenck PC 160). Different crack lengths $(a)$ were obtained $(7.57 \mathrm{~mm}<a<11.80 \mathrm{~mm})$ to yield $a / W$ ratios ranging from 0.473 to 0.738 . These specimens were tested using the same Zwick/Roell Z100 rig as used for the tensile experiments described earlier. The tests were performed in displacement control (displacement rate: $0.05 \mathrm{~mm} \mathrm{~min}^{-1}$ ). Typical raw data for different $a / W$ ratios from pseudoelastic miniature CT specimens at $295 \mathrm{~K}$ are shown in Fig. 5 as load $P$ vs. displacement $\Delta$ curves. Fig. 5 shows that all experiments yield a 


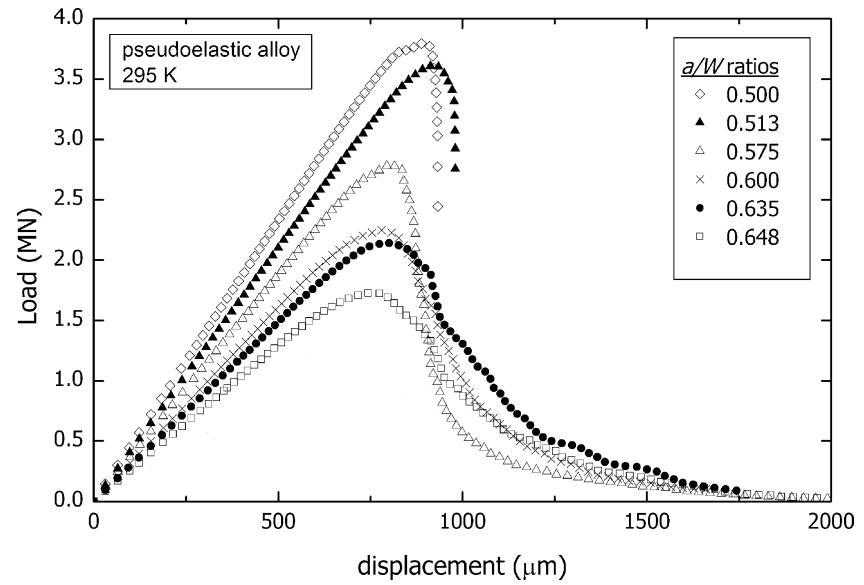

Fig. 5. Load vs. displacement curves for the pseudoelastic NiTi SMA with $a / W$ ratios ranging from 0.500 to 0.648 at $295 \mathrm{~K}$. Only some of the tests are shown here for clarity.

maximum load indicating crack propagation. As we expected, the experiment performed for the smallest $a / W$ ratio $(0.500)$ yielded the highest maximum loads. However, even in this case, there is no sharp load drop (as was observed for Al 7075), but a deviation from linearity occurs before the maximum load is reached. This indicates that the response of our pseudoelastic CT specimen to mechanical loading cannot be fully accounted for on the basis of linear elastic fracture mechanics (LEFM). This type of deviation from linearity becomes even more pronounced as $a / W$ ratios increase. We intuitively associate this effect with microstructural processes in front of the crack and we investigate these processes later. With this limitation in mind, we assessed whether prominent LEFM parameters like $K_{\mathrm{IC}}$ can account for crack stability in our alloys. We used the well-known equations for $K_{\mathrm{I}}$ and $K_{\mathrm{IC}}$ to calculate a loading parameter $K^{*}$ and a critical parameter for crack propagation $K_{\max }^{*}$ (the star indicates that we appreciate that the severe constraints imposed by the LEFM are not fully met). For $K^{*}$, we used:

$K^{*}=\left[\frac{P}{B \sqrt{W}}\right] \cdot f\left(\frac{a}{W}\right)$,

$f(a / W)$ can be obtained from the crack geometry [38]. ASTM E399 suggests that valid tests require $0.45 \leqslant a$ l $W \leqslant 0.55$ [38] and we kept this in mind when assessing our results. In the present study, we performed three types of fracture mechanics experiments for varying $a / W$ ratios. We investigated (i) a martensitic CT specimen at $295 \mathrm{~K}$; (ii) a pseudoelastic CT specimen at $295 \mathrm{~K}$; and (iii) an austenitic CT specimen at $423 \mathrm{~K}$ (above $M_{\mathrm{d}}$ ). These CT test series were performed to establish critical parameters for crack growth.

In addition to these CT tests, in situ CT experiments were performed using a miniature tensile device built by Kammrath \& Weiss GmbH. Fig. 6 shows our miniature CT specimen as mounted in this miniature test rig. Although testing is limited to much smaller displacement

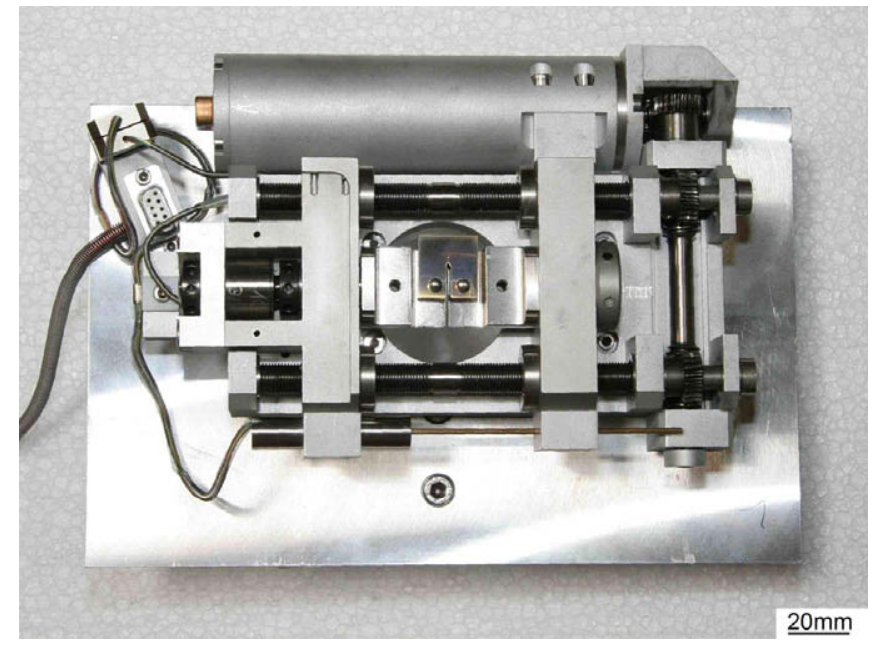

Fig. 6. An image of a miniature tensile device built by Kammrath \& Weiss $\mathrm{GmbH}$. Our miniature CT specimen is mounted in this miniature test device, which can be integrated into a scanning electron microscope as well as into a beam line of a synchrotron radiation source. This miniature test rig allows us to reproduce mechanical data, like those shown in Fig. 5, obtained with a standard size test rig.

rates, this miniature test rig allows for reproduction of the mechanical data shown in Fig. 5 obtained with a standard size test machine. This miniature test rig can be integrated into a scanning electron microscope as well as into a beam line of a synchrotron radiation facility. Using this miniature test rig, SEM images were collected using a Jeol JSM-840A scanning electron microscope operating in secondary electron imaging mode at $20 \mathrm{kV}$ and a working distance of $20 \mathrm{~mm}$ to observe the crack tip of a martensitic $(a / W=0.513)$ and a pseudoelastic $(a / W=0.506)$ CT specimen subjected to different loads between 0 and $3500 \mathrm{~N}$.

In addition to these in situ SEM experiments, we also present results from a series of in situ diffraction experiments on a pseudoelastic NiTi CT specimen obtained with this miniature test rig at the beam line BW5 of the Hamburg Synchrotron Laboratories (HASYLAB) at the German Electron Synchrotron (DESY). Diffraction measurements were performed with a $99 \mathrm{keV}(\lambda=0.0125 \mathrm{~nm})$ $\mathrm{X}$-ray beam in transmission geometry for $60 \mathrm{~s}$. An ion chamber and a diode (Keithley, Model 428) were used to locate the crack tip and to position the CT specimen by measuring the initial and transmitted beam intensity. The cross-section of the beam was $100 \times 200 \mu \mathrm{m}^{2}$ and the sample-to-camera distance was approximately $1.0 \mathrm{~m}$. Complete Debye-Scherrer diffraction rings were obtained by an image plate (MAR345) of $345 \mathrm{~mm}$ diameter with a $100 \mu \mathrm{m}$ pixel size and a 16-bit dynamic range. Calibration diffraction patterns were collected from $\mathrm{LaB}_{6}$ (NIST Standard Reference Material SRM-660). Diffraction patterns were collected on the pseudoelastic NiTi CT specimen $(a / W=0.550)$ for an unloaded $(P=0 \mathrm{~N})$ and a loaded $(P=2860 \mathrm{~N})$ condition.

The pseudoelastic NiTi CT specimen was oriented, with respect to the synchrotron beam, in two experimental 
onfigurations (perpendicular to the beam (Fig. 7a and b) and at a $45^{\circ}$ angle to the beam (Fig. $8 \mathrm{a}$ and b). In the first configuration, a diffraction map was obtained with the synchrotron beam perpendicular to the miniature pseudoelastic NiTi CT specimen, Fig. 7a. The detailed results of this study are reported in Ref. [26], and will be further evaluated and reported elsewhere. However, it should be noted here that our synchrotron diffraction data in Fig. 7a indicate that the size of the plastic zone in front of the crack in the center of the specimen is significantly smaller $(<1 \mathrm{~mm})$ than the in-plane dimensions of crack size $(1.6 \mathrm{~mm})$ and depth $(7.2 \mathrm{~mm})$, which ensures that plane strain conditions are met. Fig. $7 \mathrm{~b}$ shows the limits of the two zones where stress-induced martensite is detected in our pseudoelastic CT specimen: one close to the crack tip (tensile in nature) and the other one at the far end of the CT specimen (compressive in nature). It is important to realize that the transmitted beam in the configuration shown in Fig. 7a provides volume-average data. It indicates the presence of martensite, even for cases where stressinduced martensite only forms at the surfaces of the CT specimen (plane stress conditions) and not in the center (plane strain condition). In the second configuration (our key experiment), the miniature CT specimen is positioned at $45^{\circ}$ with respect to the incident beam (Fig. 8a). The geometry of this experiment is set up to keep the beam from crossing the plane stress surface regions and at the same time avoiding the compressive zones at the end of the CT specimen as illustrated in Fig. 8a. When stressinduced martensite is detected, it is only associated with the central crack tip regions. Fig. 8b shows a photograph of the miniature CT specimen prior to the $45^{\circ}$ diffraction experiment.

\section{Results and discussion}

\subsection{Crack loading and critical parameters}

We first consider the mechanical response of our three types (martensitic, pseudoelastic and austenitic) of miniature CT specimens. From raw data like those shown in Fig. $5, K^{*}(\Delta)$ curves can be calculated using the equation given above. Fig. 9a and b shows these stress intensity vs. displacement curves for the martensitic and pseudoelastic
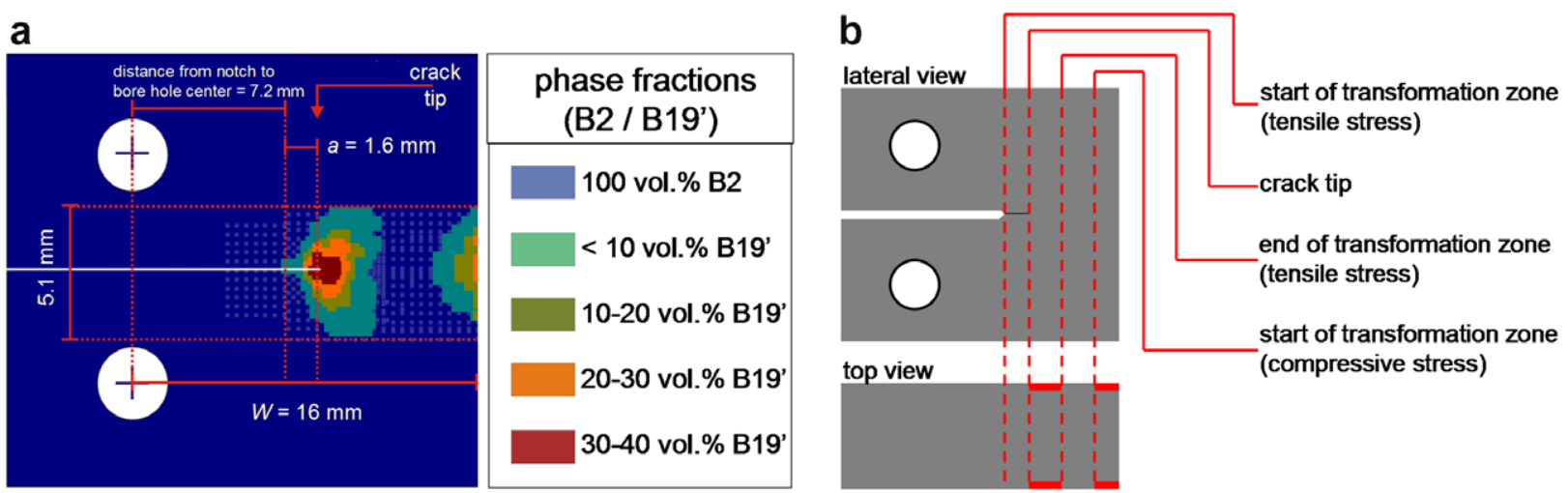

Fig. 7. (a) Phase fractions of the austenite $\mathrm{B} 2$ and martensite B19' structures for the two transformation zones in a pseudoelastic NiTi SMA CT specimen obtained by in situ synchrotron measurements at high stress intensity. Details of the diffraction results can be found in Ref. [26] and will be reported elsewhere. (b) Schematic of the first experimental configuration (CT specimen perpendicular to the diffraction beam). Note that two transformation zones can be seen just ahead of the crack and at the back of the CT specimen.
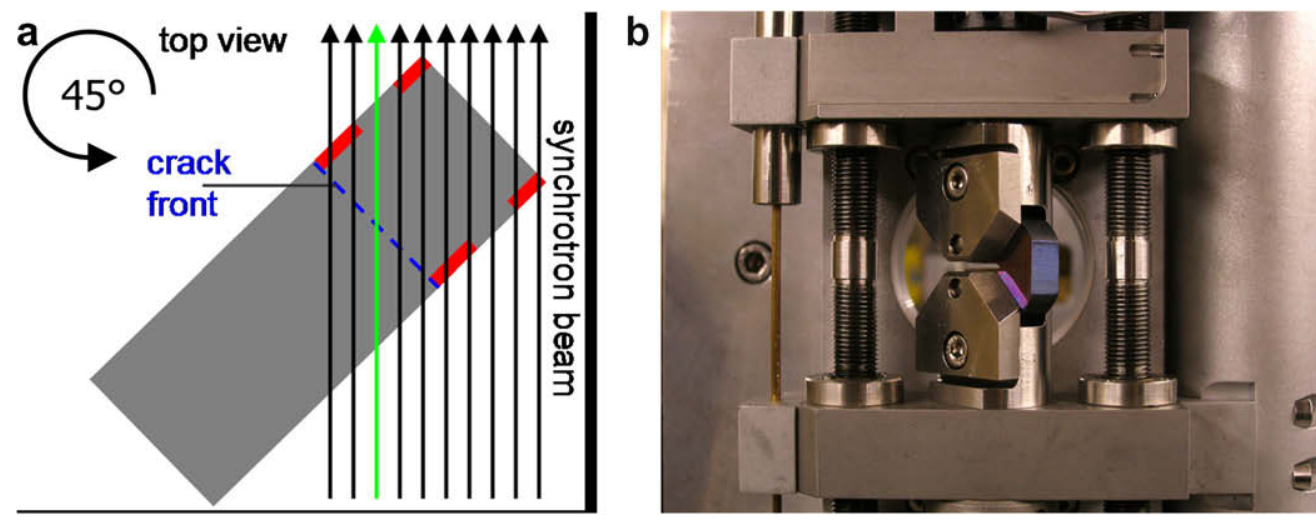

Fig. 8. (a) Schematic of the second experimental configuration (CT specimen at a $45^{\circ}$ angle to the diffraction beam) in order to detect martensitic phase fractions at high stress intensities in the plane strain condition. The black arrows indicate the central region just in front of the crack where stress-induced martensite forms upon loading. (b) Optical image of the miniature tensile rig with miniature CT specimen. 
SMAs at $295 \mathrm{~K}$ (room temperature). Fig. 9c shows the stress intensity vs. displacement curves for the austenitic material at $423 \mathrm{~K}$ (above $M_{\mathrm{d}}$ ). In the early stages of loading, all $K^{*}(\Delta)$ curves show linear elastic behavior and the
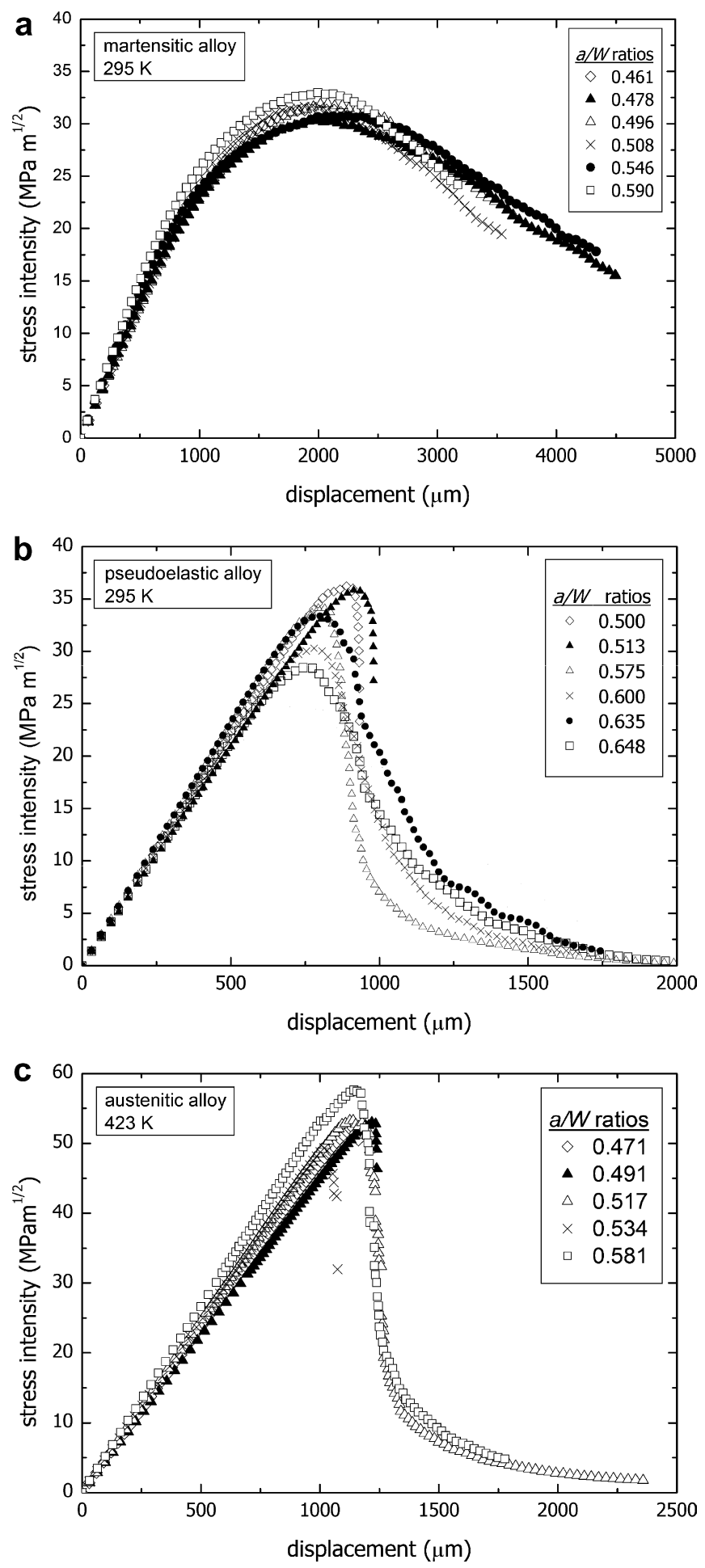

Fig. 9. Stress intensity $\left(K^{*}\right)$ vs. displacement curves of the (a) martensitic NiTi SMA at $295 \mathrm{~K}$, (b) pseudoelastic NiTi SMA at $295 \mathrm{~K}$ and (c) austenitic NiTi SMA at $423 \mathrm{~K}$ (temperature above $M_{\mathrm{d}}$ ) with varying $a / W$ ratios. $K^{*}$ displacement curves are derived from the equation given in the text for $K^{*}$
$K$-concept rationalizes the data reasonably well. In all three cases, clear maxima are observed, which indicate the start of macroscopic crack propagation. There is always a deviation from linearity before $K_{\max }^{*}$ is reached. Fig. 9a shows that this effect is much stronger and occurs significantly earlier in martensitic NiTi SMA than in the pseudoelastic (Fig. 9b) and austenitic (Fig. 9c) NiTi SMAs. This deviation is still a significant feature of the $K^{*}(\Delta)$ curves of the pseudoelastic alloy, while it almost completely vanishes in the austenitic alloy. It seems reasonable to assume that the strong nonlinearities in the martensite are related to large-scale detwinning processes. In the martensitic NiTi SMA, statistically oriented martensitic variants exist prior to loading. Upon loading, favorably oriented martensitic variants grow. This microstructural evolution is associated with large-scale macroscopic deformation. Daymond et al. [24] have detected this type of detwinning processes in martensitic CT specimens and Gollerthan et al. [19] have shown that the size of the associated pseudoplastic zone can be reasonably well rationalized using fracture mechanics concepts.

The tensile results presented in Fig. 2 suggest that detwinning starts at stresses which are significantly lower than those triggering the formation of stress-induced martensite in the pseudoelastic alloy. Therefore, larger parts of a martensitic CT specimen are affected by non-elastic processes than in the pseudoelastic CT specimen. In the analytical part of our study, we will show that small deviations from linearity in the pseudoelastic CT specimens are associated with the formation of stress-induced martensite in specimen volumes which are still large enough to cause a macroscopic effect in the $P(\Delta)$ curves (Fig. 9b). While the evolution of a detwinned martensitic variant structure requires mechanical deformation in the martensitic material, stress-induced martensitic variants form directly with preferential orientations.

The tiny deviations in the austenitic alloy are most probably related to crack tip blunting processes associated with dislocation plasticity $[40,41]$. We will show later that crack tip blunting is not observed in the martensitic and pseudoelastic SMAs. There is another significant difference between the $K^{*}(\Delta)$ curves of martensite and the two other alloys. Fig. 9b and c shows that there are sharp drops in $K^{*}$ values after $K_{\max }^{*}$ in the pseudoelastic and austenitic alloys. Here, instable cracks propagate fast. In contrast, martensitic CT specimens show a slow and steady decrease in $K^{*}$ values with increasing displacement, indicating slow crack propagation.

While the $K^{*}(\Delta)$ curves for martensitic and pseudoelastic NiTi differ, the two materials are characterized by the same critical $K_{\max }^{*}$ value, which indicates the loading condition where macroscopic cracks start to propagate. This is shown in Fig. 10, where $K_{\max }^{*}$ values are plotted as a function of specimen geometry $a / W$ for the three alloys considered. Fig. 10 shows that $K_{\max }^{*}$ is independent of specimen geometry for all three material states, within the validity range of ASTM E399-90 [38] $(0.45<a / W<0.55)$. It is interesting to 


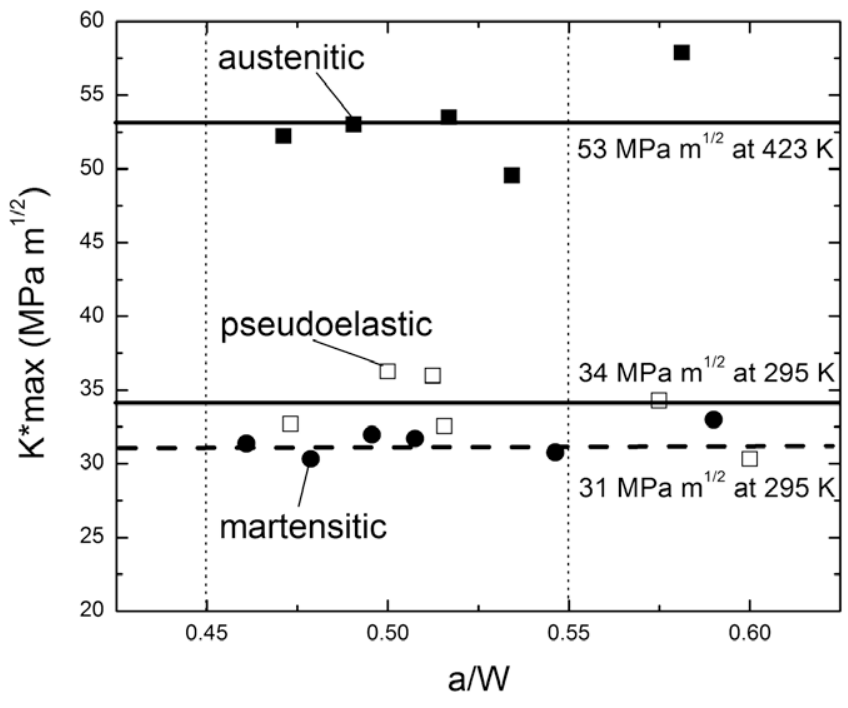

Fig. 10. Comparison of $K_{\max }^{*}$ for martensitic (filled circles), pseudoelastic (open squares) and austenitic (closed squares) NiTi SMAs. Solid (pseudoelastic and austenitic) and dashed (martensitic) lines represent mean values of $K_{\max }^{*}$ for valid $a / W$ ratios (faint dotted lines), according to ASTM E399-90, at their respective temperatures. While the $K_{\max }$ of austenitic NiTi SMA has a mean value of $53 \mathrm{MPa} \sqrt{\mathrm{m}}$ at $423 \mathrm{~K}$, much lower, but almost identical, mean values of 31 and $34 \mathrm{MPa} \sqrt{\mathrm{m}}$ for the martensitic and pseudoelastic NiTi SMAs, respectively, characterize the fracture experiments at $295 \mathrm{~K}$.

note that within this validity range, despite very different functional (see DSC charts in Fig. 1) and mechanical (see tensile data in Fig. 2) properties, martensitic and pseudoelastic NiTi SMAs are characterized by very similar $K_{\max }^{*}$ values (31 and $34 \mathrm{MPa} \sqrt{\mathrm{m}}$, respectively). This strongly suggests that, despite the different macroscopic behavior of the CT specimens prior to crack propagation, macroscopic cracks in both alloys grow into a similar microstructure: detwinned martensite. Our result on $K_{\max }^{*}$ of martensitic and pseudoelastic NiTi is in good agreement with the values reported by Daymond et al. [24] and Robertson and Ritchie [27,28], respectively.

This conclusion is indirectly supported by the fact that the austenitic CT specimen (i.e. our pseudoelastic alloy tested at $423 \mathrm{~K}$, above $M_{\mathrm{d}}$ ) shows the significantly higher $K_{\max }^{*}$ value of $53 \mathrm{MPa} \sqrt{\mathrm{m}}$. Our results show that a NiTi SMA with 50.7 at. $\%$ Ni shows a lower resistance to crack propagation when martensite forms in front of the crack tip prior to crack propagation as compared to the case where cracks grow into austenite without martensite at the crack tip. In this respect, SMAs differ from typical engineering materials where we expect a decrease of $K_{\mathrm{IC}}$ with increasing temperature, because higher temperatures result in lower elastic constants and generally promote plasticity.

\subsection{Crack tips observed by SEM}

Fig. 11a and $\mathrm{b}$ show the response of crack tip regions of martensitic and pseudoelastic NiTi as observed using SEM during in situ mechanical loading. Loads increase from $0 \mathrm{~N}$ (tops of Fig. 11a and b) to $2700 \mathrm{~N}$ (martensitic NiTi, bottom of Fig. 11a) and $3500 \mathrm{~N}$ (pseudoelastic NiTi, bottom of Fig. 11b), respectively. As illustrated in Fig. 11a and $\mathrm{b}$, the SEM micrographs reveal three important features of cracks in NiTi.

First, crack tips stay sharp and do not exhibit the typical features associated with crack tip blunting $[40,41]$. One might intuitively expect crack tip blunting in view of the deviations from linearity in the stress intensity vs. displacement curves in Fig. 9a and b. However, these deviations are not due to blunting processes. Crack tip blunting is associated with dislocation processes [40,41], and the absence of blunting in NiTi may well reflect the fact that dislocation activity at the crack tip plays a much smaller role. It seems reasonable to assume that dislocations blunt sharp crack tips, because they can account for local deformation on a finer scale than mechanical twins/martensitic variants. Further work is required to clarify whether blunting in NiTi can ever be observed when cracks grow into martensite.

Secondly, a closer inspection of the two series of micrographs shows that there is microscopic crack extension in both materials before $K_{\max }^{*}$. This can be seen when comparing the two SEM micrographs for the crack tip in martensitic NiTi loaded up to 2000 and 2700 N. At 2000 N, a small subcrack at approximately $45^{\circ}$ to the main crack grows upward. At $2700 \mathrm{~N}$, it has become the dominant crack, leaving the old crack tip (marked by white arrows pointing to the upper right in the last two micrographs in Fig. 9a) $15 \mu \mathrm{m}$ behind. Similarly, a microscopic crack extension is observed for the pseudoelastic NiTi at loads of 2750 and $3500 \mathrm{~N}$. As illustrated by white arrows pointing up in Fig. 9b, the distance of the crack tip from a ledge increases by $5 \mu \mathrm{m}$. In view of the dependence of $K^{*}$ on $a$ (see the above equation), the contribution of these microscopic undercritical crack growth events to the deviations from linearity observed in Fig. 9a and b is negligible. However, under cyclic loading conditions, the cyclic accumulation of such microscopic crack extensions may well account for the type of crack growth characteristics observed by Robertson et al. [16], where cyclic crack growth is observed in their thin CT specimen during cycling between $K_{\min }=7.5 \mathrm{MPa} \sqrt{\mathrm{m}}$ and $K_{\max }=15 \mathrm{MPa} \sqrt{\mathrm{m}}$.

Finally, a number of microstructural features in the martensitic and pseudoelastic NiTi SMAs close to the crack tip can be observed. At $0 \mathrm{~N}$ load, Fig. 11a shows randomly oriented martensitic variants in weak secondary electron contrast. Both materials show traces of pre-fatigue cracking, as can be clearly seen at $0 \mathrm{~N}$ load in the pseudoelastic NiTi (Fig. 11b, $45^{\circ}$ striations along the upper crack surface). The pseudoelastic NiTi CT specimen shows striations, which originate at the crack tip. With increasing load, these striations increase in density and size (Fig. 11b). Similar observations (at lower contrast) can be made for the martensitic NiTi CT specimen (Fig. 11a). These observations provide microstructural evidence for detwinning processes (martensitic NiTi, Fig. 11a) and the formation of stress-induced martensite (pseudoelastic NiTi, 
a
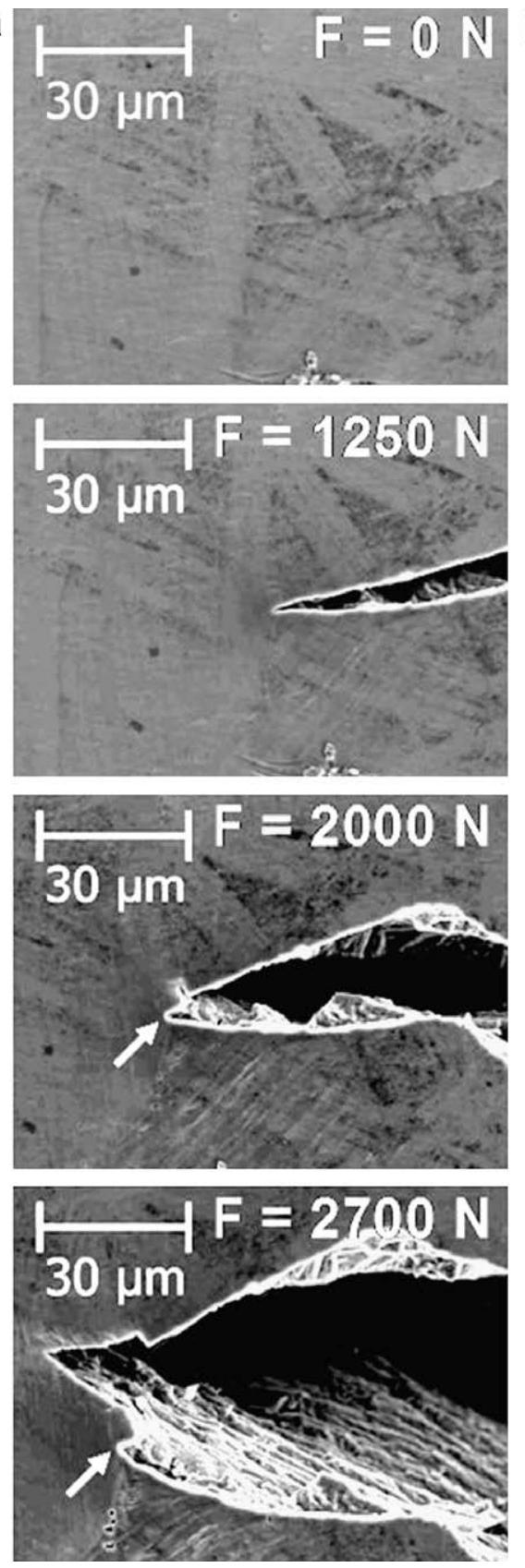
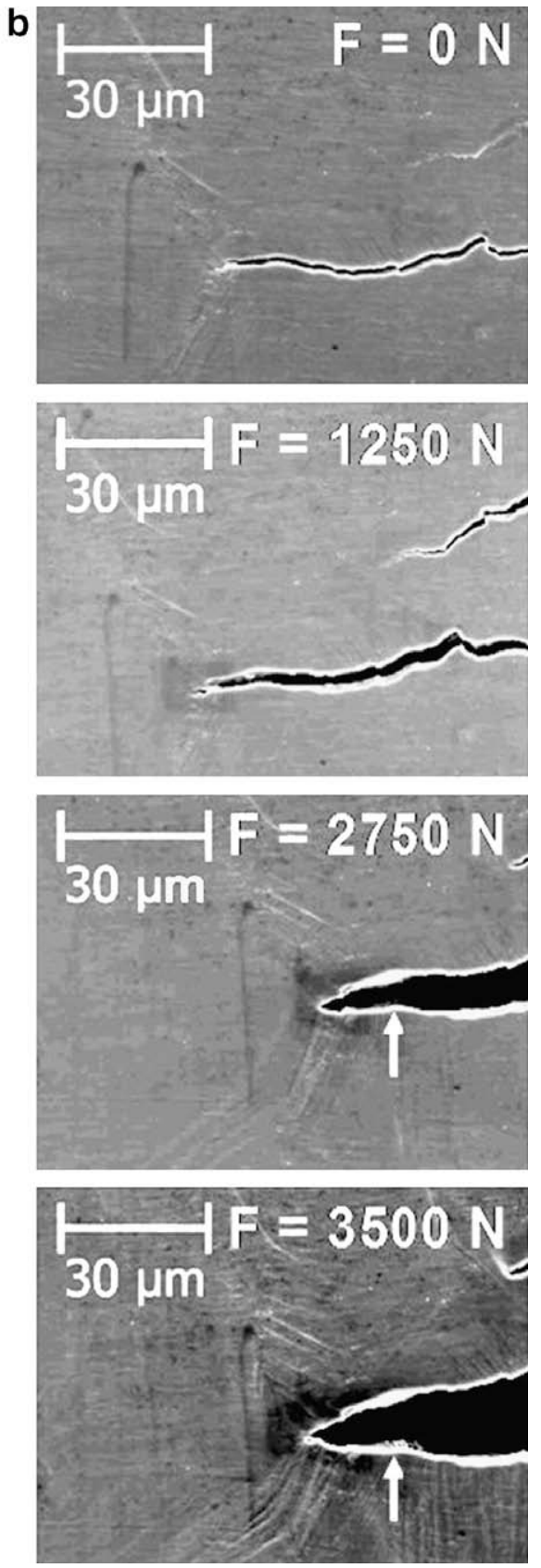

Fig. 11. Scanning electron micrographs of (a) martensitic $(a / W=0.513)$ and (b) pseudoelastic $(a / W=0.506)$ NiTi SMAs at applied loads of $0,1250,2000$ and $2700 \mathrm{~N}$ and $0,1250,2750$ and $3500 \mathrm{~N}$, respectively, during an in situ fracture experiment.

Fig. 11b), which we believe are responsible for the decrease in the stiffness of our CT specimens (deviation from linearity in the $K^{*}$ vs. displacement curves shown in Fig. 9a and $b$ ).

\subsection{Synchrotron diffraction}

In order to prove the presence of stress-induced martensite in front of the crack in the center of the CT specimen (plane strain conditions) of our pseudoelastic NiTi SMA, two diffractograms are shown in Fig. 12a and b. Although complete diffraction rings were collected, only one-quarter is shown for clarity. Fig. 12a shows diffraction data obtained after unloading. All diffraction rings have been identified and are consistent with the lattice constants of the austenite B2 structure. No martensite is observed. Although not shown here, the Debye-Scherrer diffraction rings from the CT specimen prior to loading are identical to those observed after unloading (one loading/unloading cycle). As can be clearly seen in Fig. 12b, additional diffraction rings appear when the specimen is loaded. These rings indicate the presence of stress-induced martensite and correspond to the lattice constants of the martensite $\mathrm{B} 19^{\prime}$ structure (Fig. 12b). The results presented in Fig. 12a and 

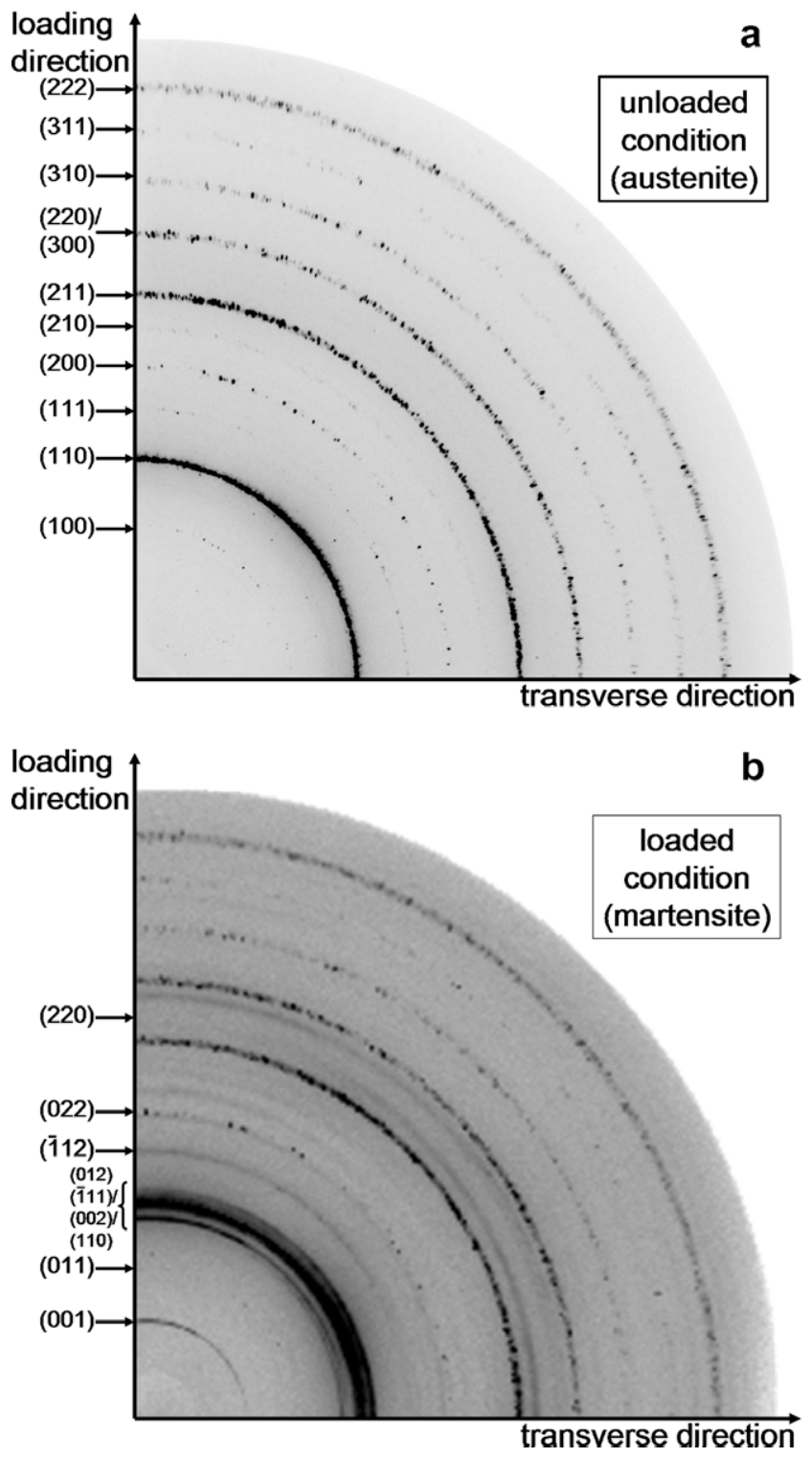

Fig. 12. One-quarter of the diffraction patterns obtained near the crack tip (a) after unloading and (b) at $2860 \mathrm{~N}$. The latter diffraction pattern shows that stress-induced martensite forms in the central region of a crack in a pseudoelastic NiTi SMA CT specimen. The former diffraction pattern shows that retransformation from the martensite $\mathrm{B} 19^{\prime}$ structure to austenite B2 structure occurs. Only a few lattice reflections are shown in the martensite diffraction pattern for clarity.

b show that stress-induced martensite forms under plane strain conditions in front of a crack in a CT specimen. This suggests that a martensitic zone forms in the crack tip region of a pseudoelastic SMA CT specimen, which is similar in nature to the well-known plastic zone that forms in ductile engineering materials (like Al 7075 and many others). The fact that all martensitic features disappear after unloading suggests that we observe reversible forwardand reverse transformations at the crack tip during loading of the CT specimen. We can exclude the formation of stabilized martensite, which cannot retransform, because it is hindered by the presence of dislocations. We cannot exclude, however, that dislocations also affect the forma- tion of stress-induced martensite in front of the crack tip; further work is required to clarify this point.

\section{Summary and conclusions}

In the present study, we investigated crack extension under static loading in three NiTi material states: martensitic (50.3 at.\% Ni), pseudoelastic $\left(50.7\right.$ at.\% Ni, $\left.T \ll M_{\mathrm{d}}\right)$ and austenitic (50.7 at. $\left.\% \mathrm{Ni}, T>M_{\mathrm{d}}\right)$. We used miniature CT specimens, which represent a reasonable compromise between the requirements for mechanical testing and the microstructural objectives of our study (small size for in situ experiments, transparency to synchrotron beam). With these miniature CT specimens, we performed mechanical and microstructural experiments. From the results obtained in the present study, the following conclusions can be drawn:

(1) CT specimens of both martensitic and pseudoelastic NiTi alloys show $P(\Delta)$ curves, which are similar to those typically observed for ductile engineering materials and show deviations from linearity prior to the onset of macroscopic crack growth. However, crack tip blunting was not observed. Instead, we suggest that the growth of favorably oriented martensitic variants (fully martensitic NiTi) and the formation of stress-induced martensite (pseudoelastic NiTi) account for these deviations from linearity. In the fully austenitic material state, these deviations from linearity are negligible.

(2) Using standard fracture mechanics procedures for $K_{\text {IC }}$, a critical parameter for macroscopic crack extension is obtained (referred to as $K_{\max }^{*}$ throughout this work). Martensitic and pseudoelastic NiTi have very different thermal properties and tensile test characteristics but show similar $K_{\max }^{*}$ values ( 31 and $34 \mathrm{MPa}$ m, respectively). In both cases, cracks grow into detwinned martensitic variant microstructures. In contrast, austenitic NiTi tested above $M_{\mathrm{d}}$, where no stressinduced martensite forms, shows a higher resistance to crack extension of $53 \mathrm{MPa} \sqrt{\mathrm{m}}$.

(3) In situ SEM studies show that crack tip blunting does not occur in martensitic and pseudoelastic NiTi. Therefore, it cannot account for the deviations from linearity observed in the $P(\Delta)$ curves. Microscopic crack growth events are observed in martensitic and pseudoelastic NiTi prior to $K_{\max }^{*}$, but the associated crack extensions are so small that they do not affect the macroscopic specimen behavior. The growth of favorably oriented martensitic variants (martensitic $\mathrm{NiTi}$ ) and the formation of stress-induced martensite (pseudoelastic NiTi) in sufficiently large parts of our miniature $\mathrm{CT}$ specimen rationalize the deviations from ideal elastic behavior. Evidence for these processes was observed in the crack tip regions of martensitic and pseudoelastic NiTi. 
(4) In situ synchrotron diffraction experiments prove that stress-induced martensite can be detected ahead of a crack in the center of the specimen (plane strain condition) in a pseudoelastic CT specimen (thickness: $10 \mathrm{~mm}$ ). The plane strain type of loading does not prohibit the formation of martensite. Our results suggest that the stress-induced formation of martensite in front of a crack produces process zones which exhibit the well-known dog-bone features associated with plastic zones in structural engineering alloys. It remains to be clarified whether dislocations also affect the process zone, where stress-induced martensite forms.

\section{Acknowledgements}

The authors acknowledge funding by the DFG through project EG101/10-2 and by the Helmholtz Association funds VH-VI-102. M.L. Young acknowledges funding from the Alexander von Humboldt Foundation.

\section{References}

[1] Hornbogen E. In: Bunk WG J, editor. Advanced structural and functional materials. Heidelberg: Springer-Verlag; 1991. p. 133-63.

[2] Saburi T. In: Otsuka K, Wayman CM, editors. Shape memory materials. Cambridge: Cambridge University Press; 1998. p. 49-96.

[3] Van Humbeeck J. Mater Sci Eng A 1999;273-275:134-48.

[4] Duerig T, Pelton A, Stockel D. Mater Sci Eng A 1999;273275:149-60.

[5] Otsuka K, Wayman CM. Shape memory materials. Cambridge: Cambridge University Press; 1998.

[6] Otsuka K, Ren X. Intermetallics 1999;7:511-28.

[7] Morgan NB. Mater Sci Eng A 2004;378:16-23.

[8] Miyazaki S. Engineering aspects of shape memory alloys. London: Butterworth-Heinemann; 1990.

[9] Yawny A, Sade M, Eggeler G. Z MetaIlkd 2005;96:608-18.

[10] Schmahl WW, Khalil-Allafi J, Hasse B, Wagner M, Heckmann A, Somsen C. Mater Sci Eng A 2004;378:81-5.

[11] Chen JH, Sun W, Wang GZ. Metall Mater Trans A 2005;36:941-55.

[12] Eggeler G, Hornbogen E, Yawny A, Heckmann A, Wagner M. Mater Sci Eng A 2004;378:24-33.

[13] Wagner M, Sawaguchi T, Kaustrater G, Hoffken D, Eggeler G. Mater Sci Eng A 2004;378:105-9.

[14] Melton KN, Mercier O. Acta Metall 1978;27:137-44.
[15] Sawaguchi T, Kaustrater G, Yawny A, Wagner M, Eggeler G. Metall Mater Trans A 2003;34:2847-60.

[16] Robertson SW, Mehta A, Pelton AR, Ritchie RO. Acta Mater 2007;55:6198-207.

[17] Stankiewicz JM, Robertson S, Ritchie RO. J Biomed Mater Res Part A 2006;81:685-91.

[18] Wang XM, Wang YF, Baruj A, Eggeler G, Yue ZF. Mater Sci Eng A 2005;394:393-8.

[19] Gollerthan S, Herberg D, Baruj A, Eggeler G. Mater Sci Eng A 2007;481-482:156-9.

[20] McKelvey A, Ritchie R. Metall Mater Trans A 2001;32:731-43.

[21] McKelvey AL, Ritchie RO. J Biomed Mater Res Part A 1999;47:301-8.

[22] Dauskardt RH, Duerig TW, Ritchie RO. In: Otsuka K. Shimizu K, editors. Symposium on shape memory materials, Materials research society international meeting on "advanced materials", vol. 9, Berlin: Springer; 1989. p. 243-9.

[23] Vaidyanathan R, Dunand DC, Ramamurty U. Mater Sci Eng A 2000;289:208-16.

[24] Daymond MR, Young ML, Almer JD, Dunand DC. Acta Mater 2007;55:3929-42.

[25] Tong W, Tao H, Zhang N. In: Furuya Y, Quandt E, Zhang Q, Inoue $\mathrm{K}$, Shahinpoor M, editors. Materials research society proceedings: symposium D, Boston (MA), vol. 785; 2003. p. D7.7.1-6.

[26] Gollerthan S. Thesis, Ruhr-Universität Bochum; 2007. p. 159.

[27] Robertson SW, Ritchie RO. J Biomed Mater Res Part B: Appl Biomater 2007;84:26-33.

[28] Robertson SW, Ritchie RO. Biomaterials 2007;28:700-9.

[29] Reed-Hill RE, Abbaschian R. Physical metallurgy principles. Boston (MA): PWS Publishing Company; 1994. p. 926.

[30] Courtney TH. Mechanical behavior of materials. Boston (MA): McGraw Hill; 2000. p. 733.

[31] Khalil Allafi J, Ren X, Eggeler G. Acta Mater 2002;50:793-803.

[32] Khalil-Allafi J, Dlouhy A, Eggeler G. Acta Mater 2002;50:4255-74.

[33] Nishida M, Wayman CM, Honma T. Metall Trans A 1986;17:1505-15.

[34] Treppmann D. Thermomechanische Behandlungen von NiTi. Thesis, Ruhr-Universität Bochum; 2006.

[35] Tadaki T, Nakata Y, Shimizu K, Otsuka K. Trans JIM 1986;27:731-40.

[36] Eggeler G, Khalil Allafi J, Gollerthan S, Somsen C, Schmahl WW, Sheptyakov D. Smart Mater Struct 2005;14:186-91.

[37] Herberg D. Werkstoffkundliche Untersuchungen zum Risswachstum in einer martensitischen Nickel-Titan-Formgedächtnislegierung. Thesis, Ruhr-Universität Bochum; 2006.

[38] American Society for Testing and Materials, Annual book of ASTM standards; 2004.

[39] Schijve J. Analysis of the fatigue phenomenon in aluminium alloys. In: NLR-TM M 2122, Amsterdam; 1964.

[40] Ritchie RO. Int J Fract 1999;100:55-83.

[41] Zhou SJ, Carlsson AE, Thomson R. Phys Rev Lett 1994;72:852-5. 